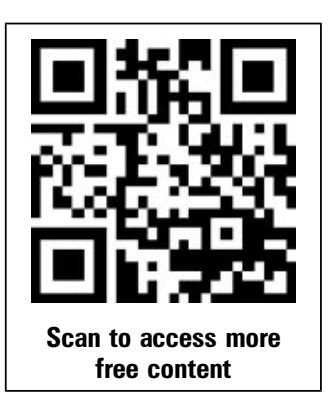
files are published online only. To view these files please visit the journal online (http://dx. doi.org/10.1136/thoraxinl2012-202403)

${ }^{1}$ Norwich Medical School, University of East Anglia, Norwich, UK

${ }^{2}$ Department of Respiratory Medicine, Bedford Hospital NHS Trust, Bedford, UK

${ }^{3}$ Respiratory Medicine Division, Department of Medicine, School of Clinical Medicine, University of Cambridge, CUHNHSFT and Papworth Hospitals, Cambridge, UK ${ }^{4}$ Department of Respiratory Medicine, Norfolk and Norwich University Hospital NHS Foundation Trust, Norwich, UK ${ }^{5}$ Department of Respiratory Medicine, Southend University Hospital NHS Foundation Trust, Essex, UK

\section{Correspondence to} Dr Andrew M Wilson, Norwich Medical School, University of East Anglia, Norwich, Norfolk NR4 7TJ, UK a.m.wilson@uea.ac.uk

Received 10 July 2012 Revised 14 October 2012 Accepted 18 October 2012 Published Online First 10 November 2012

\section{SLinked}

- http://dx.doi.org/10.1136/ thoraxjnl-2012-202531

To cite: Shulgina $L_{\text {, }}$ Cahn AP, Chilvers ER, et al. Thorax 2013;68:155-162.

\title{
Treating idiopathic pulmonary fibrosis with the addition of co-trimoxazole: a randomised controlled trial
}

\author{
Ludmila Shulgina, ${ }^{1}$ Anthony P Cahn, ${ }^{2}$ Edwin R Chilvers, ${ }^{3}$ Helen Parfrey, ${ }^{3}$ \\ Allan B Clark, ${ }^{1}$ Edward C F Wilson, ${ }^{1}$ Orion P Twentyman, ${ }^{4}$ Anthony G Davison, ${ }^{5}$ \\ John J Curtin, ${ }^{4}$ Michael B Crawford, ${ }^{4}$ Andrew M Wilson ${ }^{1,4}$
}

\section{ABSTRACT}

Background Idiopathic pulmonary fibrosis (IPF) is a fatal condition with limited treatment options. However, in a previous small study, co-trimoxazole was found to be beneficial.

Methods In a double-blind multicentre study, 181 patients with fibrotic idiopathic interstitial pneumonia (89\% diagnosed as definite/probable IPF) were randomised to receive co-trimoxazole $960 \mathrm{mg}$ twice daily or placebo for 12 months in addition to usual care. Measurements were made of forced vital capacity (FVC) (primary endpoint), diffusing capacity of carbon monoxide (DLco) and EuroQol (EQ5D)-based utility, 6-minute walk test (6MWT) and Medical Research Council (MRC) dyspnoea score (secondary endpoints). All-cause mortality and adverse events were recorded (tertiary endpoints). Results Co-trimoxazole had no effect on FVC (mean difference $15.5 \mathrm{ml}(95 \% \mathrm{Cl}-93.6$ to 124.6$))$, DLco (mean difference $-0.12 \mathrm{mmol} / \mathrm{min} / \mathrm{kPa}(95 \% \mathrm{Cl} 0.41$ to 0.17)), 6MWT or MRC dyspnoea score (intention-to-treat analysis). The findings of the per-protocol analysis were the same except that co-trimoxazole treatment resulted in a significant improvement in EQ5D-based utility (mean difference 0.12 ( $95 \% \mathrm{Cl} 0.01$ to 0.22$)$ ), a reduction in the percentage of patients requiring an increase in oxygen therapy (OR 0.05 ( $95 \% \mathrm{Cl} 0.00$ to 0.61$)$ ) and a significant reduction in all-cause mortality (co-trimoxazole 3/53, placebo 14/65, HR 0.21 (95\% Cl 0.06 to 0.78 ), $\mathrm{p}=0.02)$ ) compared with placebo. The use of cotrimoxazole reduced respiratory tract infections but increased the incidence of nausea and rash.

Conclusions The addition of co-trimoxazole therapy to standard treatment for fibrotic idiopathic interstitial pneumonia had no effect on lung function but resulted in improved quality of life and a reduction in mortality in those adhering to treatment. ISRCTN22201583

\section{INTRODUCTION}

Idiopathic pulmonary fibrosis (IPF) is the commonest form of fibrotic idiopathic interstitial pneumonia (IIP). Approximately 5000 new cases are diagnosed each year in the UK and the prevalence is rising. ${ }^{1}$ Patients usually present with symptoms of progressive breathlessness and cough resulting in impaired quality of life. Furthermore, the prognosis for people with IPF is poor as the 5 -year survival is between $20 \%$ and

\section{Key messages}

What is the key question?

- What is the efficacy and safety of the addition of 12 months of oral co-trimoxazole to standard treatment for fibrotic idiopathic interstitial pneumonia?

What is the bottom line?

- Co-trimoxazole treatment has no effect on pulmonary function or 6 min walk distance in patients with fibrotic idiopathic interstitial pneumonia (the majority of whom had idiopathic pulmonary fibrosis) but, given adequate adherence to the medication, may lead to a significant reduction in all-cause mortality associated with reduction in frequency of respiratory tract infections and improved overall health-related quality of life.

Why read on?

- Idiopathic pulmonary fibrosis (IPF) is a fatal condition with limited treatment options. This non-pharmaceutically sponsored study suggests that co-trimoxazole may have a therapeutic role in IPF. This may be due to antibiotic mechanisms.

$40 \%{ }^{2}$ and no treatments have been proved to reduce mortality. Given the poor survival and lack of effective treatment, there has been a renewed search for novel treatment options ${ }^{3}$ but few studies have achieved their primary endpoint. ${ }^{4}$

In a previous pilot study of 20 patients with IIP, co-trimoxazole treatment improved forced vital capacity (FVC), shuttle walk distance and Medical Research Council (MRC) dyspnoea score over 3 months. ${ }^{5}$ We therefore conducted a larger clinical trial to compare the efficacy and safety of the addition of 12 months of oral co-trimoxazole to standard treatment for fibrotic III.

\section{METHODS}

This was a multicentre randomised placebo-controlled double-blind parallel-group study of 12 months treatment with co-trimoxazole in 181 patients with 
fibrotic IIP. Patients were recruited from 28 university and district hospitals in England and Wales between January 2008 and December 2009. The study was conducted in accordance with good clinical practice and all participants gave written informed consent.

\section{Patients}

Eligible patients had a clinical diagnosis of fibrotic IIP including either $\mathrm{IPF}^{6}$ or fibrotic non-specific interstitial pneumonia (NSIP). Patients who were aged over 40 years, had a MRC dyspnoea score of $\geq 2$ and whose treatment regimens had remained unchanged for at least 6 weeks were entered into the study. A protocol amendment was approved to include patients not receiving immunosuppressive therapy as long as they had progressive disease with deteriorating lung function $(\geq 10 \%$ decline in FVC or $\geq 15 \%$ decline in diffusing capacity of carbon monoxide (DLCO) over the preceding 6-12 months) ${ }^{7}$ and those receiving antioxidants to reflect changes in UK prescribing practice. Women were of non-childbearing potential. Patients were excluded if a secondary cause for pulmonary fibrosis was identified, if they were receiving immunosuppressant medication other than prednisolone, azathioprine or mycophenolate mofetil, had co-trimoxazole allergy or intolerance, untreated folate or B12 deficiency, a respiratory tract infection within 2 months prior to randomisation or if they had a significant concomitant disease that could affect subject safety or influence the study outcome.

A blinded retrospective radiological review was undertaken by two specialist respiratory radiologists using published criteria ${ }^{8}$ for those patients where a histopathological diagnosis of usual interstitial pneumonia (UIP) or NSIP was not available. In addition, the high resolution CT (HRCT) scans of patients without definite IPF were scored according to the algorithm described by Fell $e t a l^{9}$ to predict the probability of IPF.

\section{Intervention}

The randomisation was performed centrally using a computergenerated randomisation code and the site research pharmacist was informed of the code by email via Norwich Clinical Trials Unit (CTU). Patients were randomised, with stratification for the site and the use of azathioprine/mycophenolate mofetil, to receive either co-trimoxazole (Essential Generics, Egham, Surrey, UK) $960 \mathrm{mg}$ (as two tablets of $480 \mathrm{mg}$ each) twice daily or an identical placebo (manufactured from the pharmacy at Guy's and St Thomas' Hospital, London), two tablets twice daily in addition to their usual care. The medication was dispensed at each study visit in containers each having 1 months' supply of the study drug. Each patient received folic acid (nonproprietary) $5 \mathrm{mg}$ once daily. The use of additional antibiotics was permitted for intercurrent infections. Adherence was assessed by a review of returns from accountability logs for each patient and was considered to be acceptable if at least $80 \%$ of study medication was taken. A password-protected web-based database (Norwich CTU) was used for data collection. Data validation was performed prior to the database lock and unblinding.

\section{Measurements}

The following measurements were assessed at 6 weeks and at 6 , 9 and 12 months following randomisation: spirometry (FVC was the primary endpoint), MRC dyspnoea score, safety laboratory tests, the EuroQol (EQ5D) questionnaire and resource use. In addition, all patients completed a St George's Respiratory Questionnaire (SGRQ) ${ }^{10}$ at screening and 6 and 12 months after randomisation. A 6-minute walk test (6 MWT) with assessment of oxygen desaturation and distance walked, ${ }^{11}$ DLCo and static lung volumes including total lung capacity was performed in selected patients where facilities were available. For the duration of the study, an assessment of tertiary endpoints including all-cause mortality, hospitalisations, the requirement for escalation of therapy and adverse events was made. The reason for admission to hospital and the cause of death was obtained from death certificates and adverse event reporting forms, which were reviewed by two blinded physicians.

The safety monitoring included screening for glucose-6phosphate deficiency at recruitment, laboratory tests (full blood count, urea and electrolytes, and liver function tests) at each visit and full blood count every 2 weeks in patients receiving azathioprine or mycophenolate mofetil. Increased monitoring of serum digoxin levels and international normalised ratio was undertaken as required. An interim blinded safety analysis was performed when $50 \%$ of patients completed $50 \%$ of their treatment to ensure that any unexpected safety issues were identified early.

\section{Statistical methods}

The primary endpoint was a change in FVC after 12 months. A sample of 128 subjects had $80 \%$ power to detect a difference of $200 \mathrm{ml}$ in FVC, assuming a SD of $400 \mathrm{ml}$. We analysed the primary outcome using a linear mixed model with site as a random effect and the use of azathioprine/mycophenolate mofetil as a fixed effect. An 'adjusted' analysis was performed by adjusting for the baseline value of the outcome. For binary outcome measures, a logistic mixed model was used and for time until death a Cox proportional hazards model was used. A per-protocol analysis excluded patients not adhering to study medication or withdrawing from the trial prior to death. Additionally, in the per-protocol analysis for deaths and FVC, we undertook a sensitivity analysis that included only individuals with a definite/probable diagnosis of IPF. ${ }^{8} 9$ A subgroup analysis of deaths by immunosuppression treatment at baseline in the per-protocol population was undertaken. The proportions of individuals with at least one adverse event were compared using the $\chi^{2}$ test. In order to assess for sensitivity of the results to missing data, a sensitivity analysis was conducted by multiple imputation. The safety analysis consisted of all patients who took at least one dose of study medication. Health state utilities were calculated from EQ5D results using standard UK health state valuations. ${ }^{12}$ An economic evaluation combining outcomes and resource use analysis will be reported in a separate paper. Analysis was performed in a blinded fashion.

\section{RESULTS}

\section{Baseline characteristics}

The intention-to-treat analysis included 181 randomised patients (figure 1). Patients had a mean age of $71.6 \pm 8.5$ years with an $\mathrm{FVC} \%$ predicted of $70.7 \pm 21.2 \%$ and DLCO $\%$ predicted of $37.5 \pm 11.5 \%$. The treatment groups were generally well matched, although patients in the co-trimoxazole group may have had shorter disease duration, and hence no adjustment to the analysis was required to account for baseline imbalance (table 1). Eleven patients (6\%) had a clinical diagnosis of fibrotic NSIP. Of these, three had their diagnosis confirmed by a surgical lung biopsy. The remaining eight patients with non-biopsyproven NSIP had a mean age of 65 years, mean DLCO of $36 \%$ predicted and two were taking prednisolone. Seventy-five patients had a definite diagnosis of IPF (histopathology or diagnostic thoracic HRCT scan). In addition, 87 were predicted to have IPF with UIP histopathology according to the criteria of 


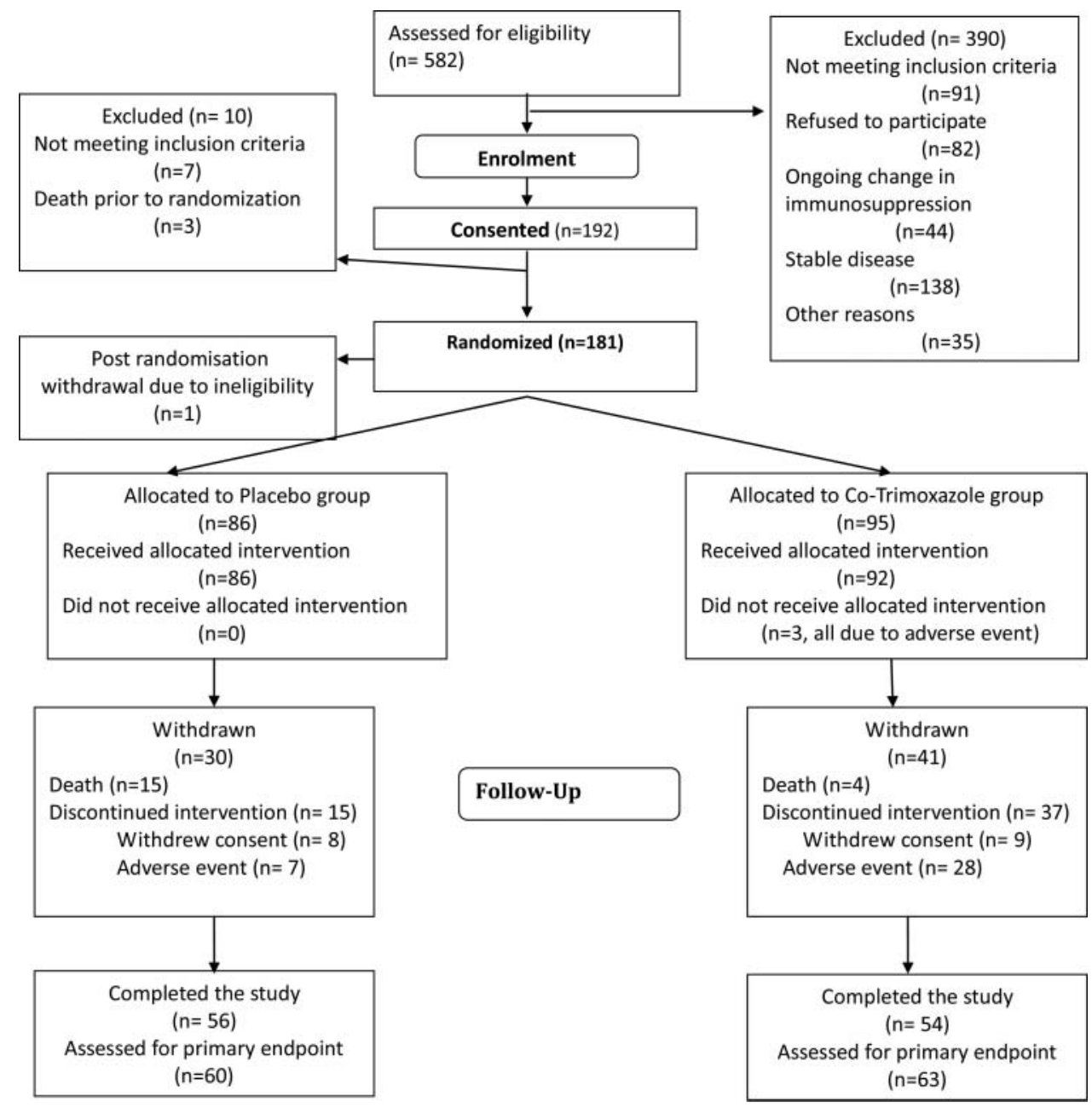

Figure 1 Disposition of patients. Lung function data required for the primary endpoint were obtained from four patients in the placebo group and nine patients in the co-trimoxazole group from routine clinical data following withdrawal from the study; n, number of patients.

Fell et $a l^{9}$ and 86 had probable IPF radiologically. ${ }^{8}$ Overall adherence to the study medication was good, with $96 \%$ of patients in the co-trimoxazole group and $90 \%$ in the placebo group receiving more than $80 \%$ of the scheduled study drug doses.

\section{Interim analysis}

The blinded interim analysis of safety showed no significant difference in the percentage of patients dying, the average number of adverse events or serious adverse events between the two groups.

\section{Efficacy}

\section{Intention-to-treat population}

There was no significant difference between treatment groups for change in pulmonary function parameters (table 2). Analysis of the other endpoints found significant differences in the symptom domain of the SGRQ and the percentage of patients requiring an increase in oxygen therapy in favour of co-trimoxazole treatment. The results of the imputation sensitivity analysis (not shown) revealed that the results were robust to missing data. No evidence was found for a subgroup effect of baseline disease severity (FVC $<$ or $>60 \%$ predicted) on FVC $(p=0.861)$ or deaths $(p=0.816)$, or baseline medication (receiving immunosuppressive therapy or not) on FVC $(p=0.594)$ or deaths $(p=0.151)$, nor did these significantly alter the treatment effect. Thirty-seven patients $(20 \%)$ had died by the end of the study, $19(22 \%)$ in the placebo group and 18 (19\%) in the co-trimoxazole group $(p=0.379$, figure 2$)$. The majority of the deaths (35/37) were due to a respiratory cause with 19 (9 in the placebo group) attributed to IPF progression itself and 11 (7 in the placebo group) as a result of pneumonia. None of the deaths were related to the use of the study drug as assessed by the investigator. Among those patients who withdrew from the study prematurely, by 12 months after recruitment five patients in the placebo arm died (four of these withdrew consent and one had an adverse event) and 15 patients in the co-trimoxazole arm died (two of these withdrew consent, one was a postrandomisation withdrawal and 12 withdrew due to an adverse event); $90 \%$ of these deaths were due to a respiratory cause (with two non-respiratory deaths in the co-trimoxazole group) and a quarter of patients in each group died as a result of pneumonia.

Per-protocol population

The results were in keeping with the intention-to-treat analysis for both primary and secondary endpoints (figure 2 and online table E1). Co-trimoxazole resulted in a significant improvement in the symptom domain of SGRQ (mean difference 5.30 units (95\% CI -11.99 to 1.40$)$ ), EQ5D-based utility (mean difference 0.12 (95\% CI 0.01 to 0.22$)$ ) and a reduction in the percentage of patients requiring an increase in oxygen therapy (OR 0.05 
Table 1 Summary of baseline characteristics for all individuals

\begin{tabular}{|c|c|c|}
\hline \multirow[t]{2}{*}{ Characteristic } & \multirow{2}{*}{$\begin{array}{l}\text { Placebo } \\
(n=86) \\
\text { Mean/number } \\
(\mathrm{SD} / \%)\end{array}$} & \multirow{2}{*}{$\begin{array}{l}\text { Co-trimoxazole } \\
\text { (n=95) } \\
\text { Mean/number } \\
\text { (SD/\%) }\end{array}$} \\
\hline & & \\
\hline Women & $21(24.4 \%)$ & $29(30.5 \%)$ \\
\hline Age (years) & $70.65(8.56)$ & $72.38(8.45)$ \\
\hline Body mass index $\left(\mathrm{kg} / \mathrm{m}^{2}\right)$ & $28.61(5.54)$ & $28.86(8.03)$ \\
\hline \multicolumn{3}{|l|}{ Smoking history } \\
\hline Current & $1(1.2 \%)$ & $1(1.1 \%)$ \\
\hline Ex-smoker & $65(75.6 \%)$ & $71(74.7 \%)$ \\
\hline Never & $20(23.3 \%)$ & $23(24.2 \%)$ \\
\hline \multicolumn{3}{|l|}{ Clinical diagnosis } \\
\hline UIP & $81(94.2 \%)$ & $89(93.7 \%)$ \\
\hline NSIP & $5(5.8 \%)$ & $6(6.3 \%)$ \\
\hline \multicolumn{3}{|l|}{ Biopsy } \\
\hline Open lung & $5 / 15(5.8 \%)$ & $3 / 14(3.2 \%)$ \\
\hline Video-assisted thoracic surgery & $10 / 15(11.6 \%)$ & $11 / 14(11.6 \%)$ \\
\hline \multicolumn{3}{|l|}{ Pathological/radiological diagnosis } \\
\hline $\begin{array}{l}\text { Definite IPF (UIP histopathology, } \\
\text { honeycombing on HRCT or in report on } \\
\text { destroyed HRCT) }\end{array}$ & 38 & 37 \\
\hline $\begin{array}{l}\text { Probable IPF (Fell probability } \\
\text { score } \geq 0.6 \text { ) }\end{array}$ & 41 & 46 \\
\hline $\begin{array}{l}\text { Probable IPF (all features consistent } \\
\text { with UIP except honeycombing on } \\
\text { HRCT or in report on destroyed HRCT) }\end{array}$ & 40 & 46 \\
\hline $\begin{array}{l}\text { Time from diagnosis to randomisation } \\
\text { (months)* }\end{array}$ & $31.1(56.8)$ & $25.5(37.1)$ \\
\hline Diagnosis within 12 months & $21(24.4 \%)$ & $25(26.3 \%)$ \\
\hline Co-existing emphysema & $9(10.5 \%)$ & $6(6.3 \%)$ \\
\hline \multicolumn{3}{|l|}{ MRC dyspnoea score } \\
\hline 2 & $17(19.8 \%)$ & $12(12.6 \%)$ \\
\hline 3 & $28(32.6 \%)$ & $42(44.2 \%)$ \\
\hline 4 & $31(36.1 \%)$ & $31(32.6 \%)$ \\
\hline 5 & $10(11.6 \%)$ & $10(10.5 \%)$ \\
\hline FVC (I) & $2.4(0.8)$ & $2.3(0.9)$ \\
\hline FVC percent predicted (\%) & $71.5(21.0)$ & $70.0(21.5)$ \\
\hline TLC (I) & $4.2(1.6)$ & $3.8(1.1)$ \\
\hline TLC percent predicted (\%) & $66.3(22.5)$ & $61.8(15.8)$ \\
\hline DLco $(\mathrm{mmol} / \mathrm{min} / \mathrm{kPa})$ & $3.5(1.9)$ & $3.2(1.6)$ \\
\hline Dıco percent predicted (\%) & $39.1(12.8)$ & $36.0(10.0)$ \\
\hline $6 \mathrm{MW}$ distance $(\mathrm{m})$ & $331.2(117.6)$ & $285.6(96.1)$ \\
\hline $6 \mathrm{MW}$ desaturation $\geq 4 \%$ & $32 / 43(74.4 \%)$ & $31 / 38(81.6 \%)$ \\
\hline SGRQ total (units) & $59.3(17.5)$ & $55.7(17.9)$ \\
\hline \multicolumn{3}{|l|}{ Treatment } \\
\hline Prednisolone & $52(60 \cdot 5 \%)$ & $54(56.8 \%)$ \\
\hline$<10$ mg/day & $11(12.8 \%)$ & $17(17.9 \%)$ \\
\hline 10-20 mg/day & $39(45.3 \%)$ & $36(37.9 \%)$ \\
\hline$>20$ mg/day & $2(2.3 \%)$ & $1(1 \%)$ \\
\hline Azathioprine & $26(30.2 \%)$ & $28(29.5 \%)$ \\
\hline Mycophenolate mofetil & $3(3.5 \%)$ & $4(4.2 \%)$ \\
\hline Carbocysteine & $2(2.3 \%)$ & $2(2.1 \%)$ \\
\hline Mecysteine & $0(0.0 \%)$ & $1(1.1 \%)$ \\
\hline $\mathrm{N}$-acetylcysteine & $20(23.3 \%)$ & $25(26.3 \%)$ \\
\hline Oxygen & $10(11.6 \%)$ & $12(12.6 \%)$ \\
\hline $\mathrm{FVC} \% \leq 60$ & $26(30.2 \%)$ & $34(35.8 \%)$ \\
\hline
\end{tabular}

${ }^{*}$ Median (IQR).

The number of patients undergoing the following measurements were: TLC: placebo 67 , co-trimoxazole 74; Dıco: placebo 72, co-trimoxazole 77; 6MWT: placebo 43, co-trimoxazole 38; SGRQ: placebo 81, co-trimoxazole 87. Units are number of patients unless indicated. DLco, diffusing capacity of carbon monoxide; FVC, forced vital capacity; HRCT, high resolution CT; IPF, idiopathic pulmonary fibrosis; MRC, Medical Research Council; 6MWT, 6-minute walk test; NSIP, non-specific interstitial pneumonia; SGRQ, St George's

Respiratory Questionnaire; TLC, total lung capacity; UIP, usual interstitial pneumonia.
(95\% CI 0.00 to 0.61$)$ ) compared with placebo. There was a significant reduction in deaths (as a tertiary endpoint) with co-trimoxazole treatment (3/53) compared with placebo ( $3 / 53$ vs $14 / 65, \mathrm{p}=0.02)$ with a HR of $0.21(95 \%$ CI 0.06 to $0.78)(\mathrm{p}=0.02)$. All 17 deaths were due to a respiratory cause with seven (40\%) resulting from gradual progression of IPF itself and five as a result of pneumonia (all in placebo arm), with the majority of non-IPF-related deaths exhibiting signs in keeping with a gradual rather than acute progression of underlying IPF (online table E2). In the placebo group, $13 \%(2 / 15)$ of those who withdrew died within 1 month of withdrawing and 6\% (2/36) of patients in the intervention group who withdrew died within 1 month. Patients receiving immunosuppressive treatment at entry into the study were more likely to die if they were in the control group (immunosuppression 12/35, no immunosuppression $2 / 30, p=0.015)$. However, baseline immunosuppressive therapy did not have an effect on mortality in the intervention group (immunosuppression 3/28, no immunosuppression $0 / 25$, $\mathrm{p}=0.238)$. The ORs for death in the intervention group relative to the control group were 0.49 (95\% CI 0.00 to 6.37 ) in the no baseline immunosuppressive medication group and $0.23(95 \%$ CI 0.06 to 0.92 ) in the baseline immunosuppressive medication group. The interaction test (ie, whether these ORs are the same) was 1.00. For patients with honeycombing on the HRCT scan, a histopathological diagnosis of UIP or predicted to have a histopathological diagnosis of UIP, ${ }^{9}$ there was a significant $(p=0.024)$ reduction in deaths with co-trimoxazole $(2 / 46)$ compared with placebo (12/62), with a HR of 0.17 (95\% CI 0.04 to 0.79$))$ (online table E3).

\section{Adverse events}

Thirty percent (28/92) in the co-trimoxazole group and $8 \%(7 / 86)$ in the placebo group withdrew due to an adverse event (figure 1 and table 3). One patient receiving co-trimoxazole and azathioprine developed severe transient neutropenia which required hospitalisation. Following this, all patients receiving azathioprine or mycophenolate mofetil had 2-weekly monitoring of their full blood count and two other patients (both receiving azathioprine and co-trimoxazole) were withdrawn because of neutropenia. There was a significant reduction in the number of patients with one or more infection in the co-trimoxazole treatment group compared with the placebo group. An increase in the reporting of nausea and rash was seen in the co-trimoxazole group. In the placebo group, $12.5 \%(7 / 56)$ had an increase in creatinine of $10 \mathrm{mmol} / \mathrm{l}$ from the baseline value compared with $59.3 \%(32 / 54)$ in the treatment group.

\section{DISCUSSION}

This study showed that co-trimoxazole had no effect on lung function parameters, 6MWT and desaturation, MRC dyspnoea score or mortality in patients with fibrotic IIP, although there was a difference in the symptom domain of SGRQ and oxygen use in the intention-to-treat analysis. The improvement in SGRQ scores might not be entirely relevant to the IPF population for two reasons: (1) the SGRQ was designed for patients with airways disease and some questions are not disease-specific to IPF; and (2) the minimum important difference of four scores accepted for chronic obstructive pulmonary diseasemight not be adequate in IPF as it has recently reported to range from five for the activity domain to eight for the symptoms domain. ${ }^{13}$ Nearly one-third of patients receiving co-trimoxazole withdrew because of side effects, mostly rash and nausea; however, there were fewer side effects related to infection in the treatment group. Based on this information, we cannot 
Table 2 Change from baseline results of primary and secondary outcomes: intention-to-treat analysis with no imputation

\begin{tabular}{|c|c|c|c|c|c|c|c|c|}
\hline \multirow{2}{*}{ Outcome } & \multicolumn{2}{|c|}{ Placebo } & \multicolumn{2}{|c|}{ Co-trimoxazole } & \multicolumn{2}{|c|}{ Unadjusted } & \multicolumn{2}{|c|}{ Adjusted for baseline } \\
\hline & $\mathrm{N}$ & Mean (SD/\%) & N & Mean (SD/\%) & $\mathrm{p}$ Value & $95 \% \mathrm{Cl}$ & $p$ Value & $95 \% \mathrm{Cl}$ \\
\hline $\mathrm{FVC}(\mathrm{ml})$ & 60 & $-195.67(288.82)$ & 63 & $-182.22(330.15)$ & 0.781 & 15.50 (-93.6 to 124.63$)$ & 0.988 & $0.00(-0.11$ to 0.11$)$ \\
\hline FVC percent predicted (\%) & 60 & $-4.79(8.70)$ & 63 & $-4.65(9.96)$ & 0.938 & $0.13(-3.14$ to 3.40$)$ & 0.978 & $0.05(-3.22$ to 3.32$)$ \\
\hline $\mathrm{TLC}(\mathrm{ml})$ & 45 & $-410.00(1328.39)$ & 44 & $-201.36(582.69)$ & 0.127 & $307.98(-87.42$ to 703.38$)$ & 0.943 & $0.01(-0.30$ to 0.32$)$ \\
\hline TLC percent predicted (\%) & 45 & $-5.70(19.54)$ & 44 & $-3.58(9.87)$ & 0.212 & $3.74(-2.14$ to 9.62$)$ & 0.972 & $-0.08(-4.73$ to 4.57$)$ \\
\hline Dıco $(\mathrm{mmol} / \mathrm{min} / \mathrm{kPa})$ & 50 & $-0.22(0.81)$ & 45 & $-0.30(0.68)$ & 0.429 & $-0.12(-0.41$ to 0.17$)$ & 0.480 & $-0.11(-0.40$ to 0.19$)$ \\
\hline DLco percent predicted (\%) & 50 & $-3.88(10.75)$ & 45 & $-3.67(8.10)$ & 0.812 & $-0.44(-4.02$ to 3.15$)$ & 0.459 & $-1.34(-4.88$ to 2.21$)$ \\
\hline SGRQ symptoms (units) & 53 & $0.76(15.83)$ & 53 & $-4.82(16.37)$ & 0.067 & $-5.73(-11.86$ to 0.40$)$ & 0.009 & $-6.88(-12.06$ to -1.70$)$ \\
\hline SGRQ activity (units) & 55 & $3.09(13.27)$ & 52 & $0.43(15.10)$ & 0.339 & $-2.64(-8.05$ to 2.77$)$ & 0.484 & $-1.82(-6.91$ to 3.27$)$ \\
\hline SGRQ impact (units) & 54 & $0.99(13.88)$ & 50 & $2.50(18.68)$ & 0.643 & $1.50(-4.83$ to 7.83$)$ & 0.690 & $1.24(-4.86$ to 7.34$)$ \\
\hline SGRQ total (units) & 52 & $1.78(11.59)$ & 49 & $0.71(13.96)$ & 0.658 & $-1.13(-6.16$ to 3.89$)$ & 0.599 & $-1.30(-6.13$ to 3.54$)$ \\
\hline 6MWT distance $(\mathrm{m})$ & 31 & $-19.48(86.49)$ & 20 & $-18.70(75.39)$ & 0.983 & 0.50 (-45.98 to 46.97$)$ & 0.835 & $-5.16(-53.55$ to 43.24$)$ \\
\hline $6 \mathrm{MWT}$ desaturation of $\geq 4 \%$ & & $31 / 35(88.6 \%)$ & & $16 / 20(80.0 \%)$ & 0.396 & $0.52(0.11$ to 2.36$)$ & 0.634 & $0.87(-2.37$ to 4.10$)$ \\
\hline EQ5D-based utility & 73 & $-0.18(0.31)$ & 71 & $-0.17(0.35)$ & 0.801 & $0.01(-0.09$ to 0.12$)$ & 0.920 & $0.10(0.01$ to 0.20$)$ \\
\hline MRC score (units) & 56 & $0.21(0.82)$ & 54 & $0.07(0.72)$ & 0.319 & $-0.15(-0.43$ to 0.14$)$ & 0.533 & $0.09(-0.37$ to 0.19$)$ \\
\hline Hospital days & 59 & $0.81(1.92)$ & 54 & $3.06(12.48)$ & 0.329 & $0.64^{*}(0.26$ to 1.56$)$ & 0.329 & $0.64(0.26$ to 1.56$)$ \\
\hline Death & & $19 / 86(22.1 \%)$ & & $18 / 95(19.0 \%)$ & 0.379 & $0.74^{*}$ (0.38 to 1.45$)$ & & \\
\hline Medicine increase & & $22 / 65(33.9 \%)$ & & $12 / 57(21.1 \%)$ & 0.122 & $0.48(0.19$ to 1.21$)$ & & \\
\hline Medicine decrease & & $5 / 57(8.8 \%)$ & & $7 / 54(13.0 \%)$ & 0.541 & 1.47 (0.43 to 5.04$)$ & & \\
\hline Oxygen increase & & $11 / 61(18.0 \%)$ & & $2 / 55(3.6 \%)$ & 0.027 & 0.15 (0.03 to 0.80$)$ & & \\
\hline Oxygen decrease & & $0 / 56(0.0 \%)$ & & $0 / 54(0.0 \%)$ & - & - & & \\
\hline
\end{tabular}

Units are number of patients unless indicated.

*HR.

DLco, total lung diffusing capacity of carbon monoxide; EQ5D, EuroQol; FVC, forced expiratory volume; ml, millilitres; MRC score, Medical Research Council Dyspnoea Score; 6MWT,

6-minute walking test; SGRQ, St George's Respiratory Questionnaire; TLC, total lung capacity.

recommend that patients with IPF are prescribed co-trimoxazole as there was no difference in the established functional measures of disease control.

The analysis of those patients adhering to the protocol (perprotocol analysis) showed that co-trimoxazole had no effect on pulmonary function, 6MWT and desaturation and MRC dyspnoea score, but led to an improvement in health-related quality of life (as measured by the EQ5D-based utility and SGRQ) and fewer patients required commencement of oxygen therapy. Our findings also raise the possibility that co-trimoxazole improves survival as there was a fivefold reduction in mortality in those patients adhering to treatment.

The difference between the findings of the intention-to-treat and per-protocol analyses may be due to improved survival in those adhering to treatment, as we would not expect any effects of co-trimoxazole to be exhibited following cessation of this treatment. Alternatively, it could be due to increased mortality in those withdrawing from the drug because of side effects or the higher withdrawal rate in the active group could be a marker of the disease severity. However, the reduction in mortality was not due to a disproportionate withdrawal of patients in the treatment arm immediately prior to death as only four patients (two from each group) withdrew from the study within 1 month of death.

The survival benefit conferred by co-trimoxazole, if real, could be due to its antimicrobial activity as there was a significant reduction in the number of infections in the group receiving active treatment. While this study was not designed to collect microbiological information, it is possible that chronic microbial colonisation of the respiratory tract in genetically susceptible hosts might contribute to alveolar epithelial injury in $\mathrm{IPF}^{14}$ Although viral pathogens have been associated with IPF, ${ }^{15}$ data are limited on the role of fungal and bacterial infection. Shimizu et $\mathrm{al}^{16}$ found a high prevalence of Pneumocystis jirovecii colonisation (23.3\%) among patients with IPF and collagen vascular disease. Richter et $\mathrm{al}^{17}$ demonstrated that $36 \%$ of nonimmunosuppressed IPF patients without clinical features of a respiratory tract infection grew pathogenic bacteria from their bronchoalveolar lavage fluid compared with none of the controls. Furthermore, it is known that the mortality of IPF is greater in the winter even when recognised infection is excluded, ${ }^{18}$ and infections can trigger acute decline in IPF leading to death. ${ }^{19}$

It is also possible that co-trimoxazole has effects that are independent of its antibiotic action. Co-trimoxazole has been shown to have an immunomodulatory effect leading to a reduction in the rate of relapse in patients with granulomatosis with polyarteritis (formerly Wegener's granulomatosis) ${ }^{20}$ and to beneficial effects in rheumatoid arthritis. ${ }^{21}$ In vitro studies suggest that co-trimoxazole may reduce neutrophil-derived oxidative stress ${ }^{22}$ and/or divert the profibrotic Th2-mediated responses to a more favourable Th1 environment. ${ }^{23}$

In keeping with retrospective data, ${ }^{24}$ we have also shown that treatment with immunosuppression may be a predictor of increased mortality, as mortality in the control group was greater in those patients receiving immunosuppressive therapy at baseline. Indeed, the interim safety analysis from the study of prednisolone, azathioprine and $\mathrm{N}$-acetylcysteine for pulmonary fibrosis reported that treatment with immunosuppression was associated with increased mortality compared with placebo. ${ }^{25}$

It is not possible to determine whether co-trimoxazole affects acute exacerbations of IPF owing to the small number of IPF-related deaths in this study. As many of our patients were on immunosuppressive treatment at recruitment, co-trimoxazole 
Figure 2 Kaplan-Meier plots of time until death based on intention-to-treat and per-protocol populations. There was no difference in mortality between co-trimoxazole (19/86) and placebo $(18 / 95)$ at 12 months in the intention-to-treat analysis but there was a significant difference in the mortality between the co-trimoxazole $(3 / 53)$ and placebo $(14 / 65)$ groups at 12 months which amounted to a HR of $0.2(95 \% \mathrm{Cl} 0.06$ to 0.78$)$ in the per-protocol analysis.

\section{Intention-to-treat}

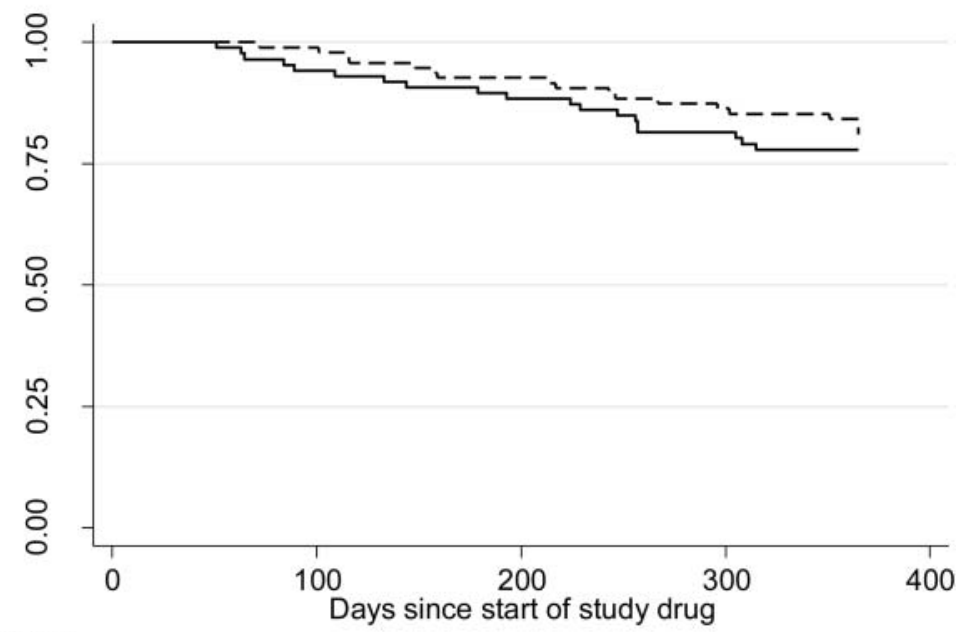

Number at risk

Control 86

Intervention 95

(5)

\section{1}

(5) 76

(6)

(6)

70

(3)

(5)

0

Control - - - - Intervention

\section{Per-protocol}

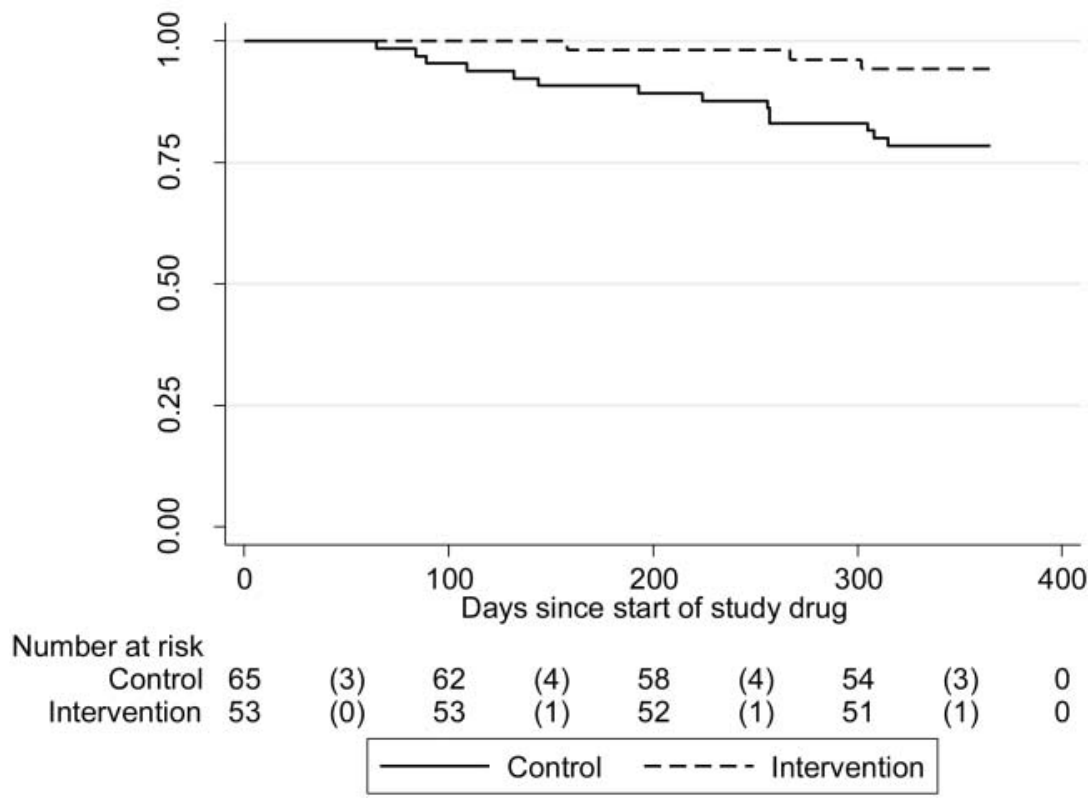

may have acted by preventing immunosuppression-related infections. However, in all analyses, adjustment was made for the effect of treatment with azathioprine/mycophenolate mofetil at baseline, and the treatment effect of co-trimoxazole did not appear to be confined to those receiving immunosuppressive therapy in the subgroup analysis.

The study described here was conducted prior to the most recent guidelines for the diagnosis and management of $\mathrm{IPF}^{3}$ Patients were entered into the study based on clinical and HRCT findings and few patients had histological confirmation of their disease, which reflects current clinical practice in the UK and is similar to other clinical trials. ${ }^{26}$ However, both of our sensitivity analyses of patients with definite/probable IPF showed the same degree of mortality benefit with co-trimoxazole. A high proportion of patients on immunosuppressive therapy at recruitment (which finished in December 2009) could be explained by the approach was based on IPF guideline recommendations from $2000 .^{27}$ Interestingly, the British Thoracic Society national interstitial lung disease survey with data collected during late 2010 and early 2011 showed that around half of responders (total of 120) continued to use prednisolone $(55 \%)$ and azathioprine (49\%) for the treatment of IPF at the time. ${ }^{28}$

In summary, while we have been unable to demonstrate that co-trimoxazole has an effect on disease progression in patients with IPF, our data provide some evidence that treatment with co-trimoxazole may improve survival in people with IPF and, if so, the mechanism might be by reduction of respiratory infection. Further studies to verify these findings are needed. fact that most of the cases were prevalent so their treatment 
Table 3 Number of adverse events by category and safety group

\begin{tabular}{|c|c|c|c|c|}
\hline Group & Subgroup & $\begin{array}{l}\text { Placebo } \\
\text { Number of } \\
\text { individuals } \\
\text { with } \geq 1(\%)\end{array}$ & $\begin{array}{l}\text { Co-trimoxazole } \\
\text { Number of } \\
\text { individuals with } \\
\geq 1(\%)\end{array}$ & $\begin{array}{l}p \\
\text { Value }\end{array}$ \\
\hline Blood disorder & & $3(3.5)$ & $6(6.5)$ & 0.356 \\
\hline Cardiac disorder & & $9(10.5)$ & $3(3.3)$ & 0.055 \\
\hline Dental condition & & $1(1.2)$ & $2(2.2)$ & 1 \\
\hline Ear disorder & & $1(1.2)$ & $0(0.0)$ & 0.483 \\
\hline Eye disorder & & $3(3.5)$ & $5(5.4)$ & 0.722 \\
\hline $\begin{array}{l}\text { General } \\
\text { disorders }\end{array}$ & & $14(16.3)$ & 17 (18.5) & 0.699 \\
\hline Gastrointestinal & & $21(24.4)$ & 41 (44.6) & 0.005 \\
\hline & Nausea & $6(7.0)$ & 17 (18.5) & 0.022 \\
\hline $\begin{array}{l}\text { Immune system } \\
\text { disorder }\end{array}$ & & $1(1.2)$ & $0(0.0)$ & 0.483 \\
\hline Infection & & $59(68.6)$ & $38(41.3)$ & $<0.001$ \\
\hline & Pneumonia & $8(9.3)$ & $0(0.0)$ & 0.002 \\
\hline & LRTI & $38(44.2)$ & $27(29.4)$ & 0.04 \\
\hline & URTI & $14(16.3)$ & $6(6.5)$ & 0.039 \\
\hline Injury & & $0(0.0)$ & $3(3.3)$ & 0.247 \\
\hline Investigations & & $7(8.1)$ & $11(12.0)$ & 0.399 \\
\hline $\begin{array}{l}\text { Metabolic } \\
\text { disorder }\end{array}$ & & $8(9.3)$ & $13(14.1)$ & 0.318 \\
\hline $\begin{array}{l}\text { Muscle and } \\
\text { tissue disease }\end{array}$ & & $11(12.8)$ & $12(13.0)$ & 0.96 \\
\hline Neoplasia & & $4(4.7)$ & 1 (1.1) & 0.199 \\
\hline Nervous system & & $11(12.8)$ & $11(12.0)$ & 0.866 \\
\hline $\begin{array}{l}\text { Medical and } \\
\text { surgical } \\
\text { procedures }\end{array}$ & & $5(5.8)$ & $1(1.1)$ & 0.108 \\
\hline Psychiatric & & $4(4.7)$ & $5(5.4)$ & 1 \\
\hline $\begin{array}{l}\text { Renal and } \\
\text { urinary disease }\end{array}$ & & $3(3.5)$ & $3(3.3)$ & 1 \\
\hline $\begin{array}{l}\text { Reproductive } \\
\text { and breast }\end{array}$ & & $2(2.3)$ & $0(0.0)$ & 0.232 \\
\hline Respiratory & & $39(45.4)$ & $35(38.0)$ & 0.323 \\
\hline Skin disorder & & $4(4.7)$ & $14(15.2)$ & 0.019 \\
\hline $\begin{array}{l}\text { Vascular } \\
\text { disorders }\end{array}$ & & $7(8.1)$ & $9(9.8)$ & 0.702 \\
\hline None & & $21(24.4)$ & $16(17.4)$ & 0.248 \\
\hline
\end{tabular}

Acknowledgements The authors thank the local principal investigators (detailed below), the research nursing staff, Dr Veronica Varney, Dr Julie Anderson, Mrs Sue Steel, Mr Tony Dyer (Norwich CTU), NIHR Cambridge Biomedical Research Centre, Papworth Research and Development Department, and the patients who made this study possible. Local principal investigators: R Allcock (Queen Elizabeth Hospital, Gateshead), M Azher (Bedford Hospital), D Boldy (Pilgrim Hospital, Boston), T Cotter (James Paget University Hospital, Great Yarmouth), M Darmalingam (Whipps Cross University Hospital, London), J Douse (Ipswich Hospital), D Ellis (James Paget University Hospital, Great Yarmouth), I Forrest (Royal Victoria Infirmary, Newcastle), K Harrison (Morriston Hospital, Swansea), P Hawkins (Colchester Hospital), T Howes (Colchester Hospital), S lles (Royal Cornwall Hospital, Truro), N Innes (Ipswich Hospital), O Khair (Birmingham City Hospital), C Leonard (Wythenshawe Hospital, Manchester), J Mann (New Cross Hospital, Wolverhampton), R O'Driscoll (Salford Royal University Hospital), A Pawlowicz (Queen Elizabeth Hospital, Kings Lynn), P Pillai (Luton Hospital), A Promnitz (Ipswich Hospital), J Ramsay (Luton Hospital), L Spencer (Aintree University Hospital, Liverpool), M Spiteri (North Staffordshire University Hospital), D Stock (South Tyneside Hospital, South Shields), E Thomas (Bedford Hospital), C Warburton (Aintree University Hospital, Liverpool), J White (West Suffolk Hospital), M Whyte (University of Sheffield), J Wiggins (Heatherwood and Wexham Park Hospitals, Slough), B Yung (Basildon Hospital), H Yussef (Chorley and South Ribble Hospital). This paper presents independent research commissioned by the National Institute for Health Research (NIHR) under its Research for Patient Benefit (RfPB) Programme. The views expressed are those of the author(s) and not necessarily those of the NHS, the NIHR or the Department of Health.
Contributors AMW was the chief investigator and $L S$ was the study coordinator. EC chaired the steering committee. APC, EC, ABC, EW, OT, TD, JC and AMW participated in study conception and design. Study research sites and LS were responsible for data collection. $L S$ and $A M W$ were responsible for data validation. $L S, A P C, E C, H P, O T, T D, J C, A M W, A B C$ and EW participated in data analysis, $A B C$ undertook the statistical analysis. $J C$ and $M C$ provided radiological review. All authors participated in data interpretation, writing and revision of the report and approval of the final version.

Funding This study was funded by East Anglia Thoracic Society, the National Institute for Health Research for Patient Benefit (RfPB) Programme (grant reference number PB-PG-0906-11116) and a Boehringer Ingelheim non-commercial educational grant.

Competing interests APC is an employee of GlaxoSmithKline but has no conflict of interest to declare.

\section{REFERENCES}

1 Navaratnam V, Fleming KM, West J, et al. The rising incidence of idiopathic pulmonary fibrosis in the UK. Thorax 2011;66:462-7.

2 Nicholson AG, Colby TV, du Bois RM, et al. The prognostic significance of the histologic pattern of interstitial pneumonia in patients presenting with the clinical entity of cryptogenic fibrosing alveolitis. Am J Respir Crit Care Med 2000;162:2213-17.

3 Raghu G, Collard HR, Egan JJ, et al. An official ATS/ERS/JRS/ALAT statement: idiopathic pulmonary fibrosis: evidence-based guidelines for diagnosis and management. Am J Respir Crit Care Med 2011;183:788-824.

4 Spagnolo P, Del Giovane C, Luppi F, et al. Non-steroid agents for idiopathic pulmonary fibrosis. Cochrane Database Syst Rev 2010;(9):CD003134.

5 Varney VA, Parnell HM, Salisbury DT, et al. A double blind randomised placebo controlled pilot study of oral co-trimoxazole in advanced fibrotic lung disease. Pulm Pharmacol Thera 2008;21:178-87.

6 Anonymous. American Thoracic Society. Idiopathic pulmonary fibrosis: diagnosis and treatment. International consensus statement. American Thoracic Society (ATS), and the European Respiratory Society (ERS). Am J Respir Crit Care Med 2000;161:646-64.

7 Bradley B, Branley HM, Egan JJ, et al. Interstitial lung disease guideline: the British Thoracic Society in collaboration with the Thoracic Society of Australia and New Zealand and the Irish Thoracic Society. Thorax 2008;63(Suppl 5):v1-58.

8 Silva $\mathrm{Cl}$, Muller NL, Hansell DM, et al. Nonspecific interstitial pneumonia and idiopathic pulmonary fibrosis: changes in pattern and distribution of disease over time. Radiology 2008;247:251-9.

9 Fell CD, Martinez FJ, Liu LX, et al. Clinical predictors of a diagnosis of idiopathic pulmonary fibrosis. Am J Respir Crit Care Med 2010;181:832-7.

10 Chang JA, Curtis JR, Patrick DL, et al. Assessment of health-related quality of life in patients with interstitial lung disease. Chest 1999;116:1175-82.

11 American Thoracic Society. ATS statement: guidelines for the six-minute walk test. Am J Respir Crit Care Med 2002;166:111-17.

12 Dolan P. Modeling valuations for EuroQol health states. Med Care 1997:35:1095-108.

13 Swigris JJ, Brown KK, Behr J, et al. The SF-36 and SGRQ: validity and first look at minimum important differences in IPF. Respir Med 2010;104:296-304.

14 Vannella KM, Moore BB. Viruses as co-factors for the initiation or exacerbation of lung fibrosis. Fibrogenesis Tissue Repair 2008;1:2.

15 Hayashi S, Hogg JC. Adenovirus infections and lung disease. Curr Opin Pharmacol 2007;7:237-43.

16 Shimizu $Y$, Sunaga N, Dobashi $K$, et al. Serum markers in interstitial pneumonia with and without Pneumocystis jirovecii colonization: a prospective study. BMC Infect Dis 2009:9:47.

17 Richter AG, Stockley RA, Harper L, et al. Pulmonary infection in Wegener granulomatosis and idiopathic pulmonary fibrosis. Thorax 2009;64:692-7.

18 Olson AL, Swigris JJ, Raghu G, et al. Seasonal variation: mortality from pulmonary fibrosis is greatest in the winter. Chest 2009;136:16-22.

19 Huie TJ, Olson AL, Cosgrove GP, et al. A detailed evaluation of acute respiratory decline in patients with fibrotic lung disease: aetiology and outcomes. Respirology 2010;15:909-17.

20 Stegeman CA, Tervaert JW, de Jong PE, et al. Trimethoprim-sulfamethoxazole (co-trimoxazole) for the prevention of relapses of Wegener's granulomatosis. Dutch Co-Trimoxazole Wegener Study Group. N Engl J Med 1996;335:16-20.

21 Rozin A, Schapira D, Braun-Moscovici Y, et al. Cotrimoxazole treatment for rheumatoid arthritis. Semin Arthritis Rheum 2001;31:133-41.

22 Anderson R, Grabow G, Oosthuizen R, et al. Effects of sulfamethoxazole and trimethoprim on human neutrophil and lymphocyte functions in vitro: in vivo effects of co-trimoxazole. Antimicrob Agents Chemother 1980;17:322-6.

23 Hess DA, O'Leary EF, Lee JT, et al. Inhibition of cytokine production and interference in IL-2 receptor-mediated Jak-Stat signaling by the hydroxylamine metabolite of sulfamethoxazole. FASEB J 2001;15:1855-7. 


\section{Interstitial lung disease}

24 du Bois RM. Idiopathic pulmonary fibrosis: present understanding and future options. Eur Respir Rev 2011;20:132-3.

25 Raghu G, Anstrom KJ, King TE Jr., et al. Prednisone, azathioprine, and $\mathrm{N}$-acetylcysteine for pulmonary fibrosis. N Engl J Med 2012;366:1968-77.

26 Kubo H, Nakayama K, Yanai M, et al. Anticoagulant therapy for idiopathic pulmonary fibrosis. Chest 2005;128:1475-82.
27 American Thoracic Society. Idiopathic pulmonary fibrosis: diagnosis and treatment. International consensus statement. American Thoracic Society (ATS) and the European Respiratory Society (ERS). Am J Respir Crit Care Med 2000;161:646-64.

28 Dempsey OJ, Welham S, Hirani N. BTS National Interstitial Lung Diseases (ILD) Survey 2010-2011. Thorax 2011;66(Suppl 4):A102. 